Article

\title{
Integrated Capacitive Deionization and Humidification- Dehumidification System for Brackish Water Desalination
}

\author{
Sadam-Hussain Soomro ${ }^{1}$, Yusufu Abeid Chande Jande ${ }^{2,3}$, Salman Memon ${ }^{4}{ }^{\circledR}$, Woo-Seung Kim ${ }^{5}$ \\ and Young-Deuk Kim ${ }^{5,6, *(1)}$
}

1 Department of Mechanical Convergence Engineering, Hanyang University School of Mechanical Engineering, 222 Wangsimni-ro, Seongdong-gu, Seoul 04763, Korea; saddamarif7@gmail.com

2 Department of Materials and Energy Sciences and Engineering, The Nelson Mandela African Institution of Science and Technology, Arusha P.O. Box 447, Tanzania; yusufu.jande@nm-aist.ac.tz

3 Water Infrastructure and Sustainable Energy Futures (WISE-Futures) Center, The Nelson Mandela African Institution of Science and Technology, The Nelson Mandela Road, Arusha P.O. Box 447, Tanzania

4 Department of Mechanical Design Engineering, Hanyang University, 55 Hanyangdaehak-ro, Sangnok-gu, Ansan 15588, Gyeonggi-do, Korea; salman0258@gmail.com

5 Department of Mechanical Engineering, Hanyang University, 55 Hanyangdaehak-ro, Sangnok-gu, Ansan 15588, Gyeonggi-do, Korea; wskim@hanyang.ac.kr

6 BK21 FOUR ERICA-ACE Center, Hanyang University, 55 Hanyangdaehak-ro, Sangnok-gu, Ansan 15588, Gyeonggi-do, Korea

* Correspondence: youngdeuk@hanyang.ac.kr

Citation: Soomro, S.-H.; Jande, Y.A.C.; Memon, S.; Kim, W.-S.; Kim, Y.-D. Integrated Capacitive Deionization and HumidificationDehumidification System for Brackish Water Desalination. Energies 2021, 14, 7641. https://doi.org/ 10.3390/en14227641

Academic Editor: Noam Lior

Received: 11 October 2021

Accepted: 10 November 2021

Published: 15 November 2021

Publisher's Note: MDPI stays neutral with regard to jurisdictional claims in published maps and institutional affiliations.

Copyright: (c) 2021 by the authors. Licensee MDPI, Basel, Switzerland. This article is an open access article distributed under the terms and conditions of the Creative Commons Attribution (CC BY) license (https:// creativecommons.org/licenses/by/ $4.0 /)$.

\begin{abstract}
A hybrid capacitive deionization and humidification-dehumidification (CDI-HDH) desalination system is theoretically investigated for the desalination of brackish water. The CDI system works with two basic operations: adsorption and regeneration. During adsorption, water is desalted, and during the regeneration process the ions from electrodes are detached and flow out as wastewater, which is higher in salt concentration. This wastewater still contains water but cannot be treated again via the CDI unit because CDI cannot treat higher-salinity waters. The discarding of wastewater from CDI is not a good option, since every drop of water is precious. Therefore, CDI wastewater is treated using waste heat in a process that is less sensitive to high salt concentrations, such as humidification-dehumidification $(\mathrm{HDH})$ desalination. Therefore, in this study, CDI wastewater was treated using the $\mathrm{HDH}$ system. Using the combined system (CDI-HDH), this study theoretically investigated brackish water of various salt concentrations and flow rates at the CDI inlet. A maximum distillate of $1079 \mathrm{~L} /$ day was achieved from the combined system and the highest recovery rate achieved was $24.90 \%$ from the $\mathrm{HDH}$ unit. Additionally, two renewable energy sources with novel ideas are recommended to power the CDI-HDH system.
\end{abstract}

Keywords: humidification-dehumidification; capacitive deionization; desalination; brackish water; hybrid system

\section{Introduction}

Earth's quantity of freshwater-one of the vital components for life-is shrinking every day, and the situation is further exacerbated by rapid population growth. The prediction in [1] revealed that by 2040, two-thirds of the world's population will suffer from a dearth of freshwater. Although the surface of the Earth is $70 \%$ water, $97 \%$ of that resides in oceans, which have a much higher salt concentration. The salinity of seawater is very high, containing dissolved salts ranging from 10,000 to 35,000 parts per million (ppm). Additionally, the sea contains many impurities like industrial waste materials, domestic waste, mortal remains, sewage waste, etc. Of the remaining $3 \%$ of the water on Earth, the majority (77\%) is frozen water trapped in glaciers, $1 \%$ is in lakes and rivers, and $22 \%$ is groundwater. The problem is increasingly serious because the groundwater is also 
becoming salty due to agricultural chemicals, septic waste, landfill, road salts, underground pipes, hazardous waste, etc., which result in the dissolution of minerals such as anhydrite, carbonates, gypsum, fluoride salts, etc., into groundwater. Therefore, seawater and polluted groundwater are unfit for domestic and industrial use. Water that has a salinity of less than $500 \mathrm{ppm}$ is considered to be freshwater $[2,3]$. To cope with the soaring demand for freshwater, the only choice for producing freshwater is to remove excess salt from seawater and/or brackish water using desalination techniques. Desalination processes such as forward osmosis (FO) and reverse osmosis (RO) require pressure energy to permit the water to flow through the membrane. Multi-stage flash (MSF), multi-effect distillation (MED), solar still (SS), humidification-dehumidification (HDH), and membrane distillation (MD) include phase change and require thermal energy. Capacitive deionization (CDI) and electrodialysis are performed using electrical energy.

In addition to the technologies described above, a hybrid desalination system may be considered. A hybrid desalination system combines two or more technologies. The hybrid system can have more benefits such as higher productivity, energy savings, higher efficiency, and maximizing the overall recovery. Several hybrid desalination systems have been developed during the last few decades and offer promising and improved performance.

Leon et al. [4] integrated RO with an MSF unit, which provided the benefit of blending the products of these two systems. This results in the operation of RO units with higher total dissolved salts (TDS) and consequently lowers the replacements of membranes and reduces cost by nearly $40 \%$. A hybrid process termed "MEDAD" desalination, which is the combination of MED and adsorption cycle (AD), was proposed by Shahzad et al. [5]. Their combination allowed MED stages to run at a lower ambient temperature (about $5{ }^{\circ} \mathrm{C}$ ) compared to the conventional multi-effect distillation (MED) system. The hybrid MEDAD increased productivity from 2.5-fold to 3-fold as compared to MED at the same top brine condition. An HDH desalination system coupled with a heat pump working on a vapor compression cycle was proposed by Lawal et al. [6]. They conducted an experimental and theoretical study of a system working with an open-water and open-air circulation mode. Their system produced a maximum GOR of 2.72 , with a recovery ratio of $2.56 \%$. Meanwhile, the distillate rate from the system was $9.23 \mathrm{~kg} / \mathrm{h}$ with a unit cost of $15.14 \mathrm{USD} / \mathrm{m}^{3}$.

Emad et al. [7] combined the MD and RO units in series for desalting geothermal brackish water. Brine from the MD unit was fed into the RO unit and recycled again to the MD unit. The recycling was found to be highly effective and maximized the freshwater production rate, increased the recovery rate, and reduced the specific energy consumption. The overall recovery rate in the hybrid MD-RO model increased to $40 \%$ with an energy cost of $0.9 \mathrm{USD} / \mathrm{m}^{3}$. The energy cost per cubic meter of water produced was USD 0.9. A VMD (vacuum membrane distillation)-RO hybrid system, where VMD was the complimentary process to the $\mathrm{RO}$ unit in order to concentrate the $\mathrm{RO}$ brines further, was proposed by Mericq et al. [8]. Their hybrid system showed a rise in the recovery of the unit. Lawal and Antar [9] investigated an HDH desalination system coupled with a heat pump. They compared three configurations (A, B, and C) in their system. In A, seawater is heated in a brine heat exchanger (HX) after leaving the dehumidifier; in $B$, air is heated in an $\mathrm{HX}$ after leaving the humidifier; while in $\mathrm{C}$, no $\mathrm{HX}$ was employed. Their system produced a recovery of $23.3 \%, 23.1 \%$, and $15.23 \%$ with configurations $\mathrm{C}, \mathrm{B}$, and $\mathrm{A}$, respectively.

Alessandra and Enrico [10] integrated RO with the MD desalination system and performed an energy and exergy analysis of the hybrid system. In their configuration the brine from RO was treated inside the MD unit. The Nano filtration (NF) process was utilized to pretreat the feed prior to using the RO unit. The authors revealed that the proposed system is an alternative to $\mathrm{RO}$ and also to thermal desalination techniques. Tabrizi et al. [11] performed an experimental analysis of a cascade solar still (SS) with HDH desalination for the weather conditions of Zahedan, Iran. The daily production of the SS with and without $\mathrm{HDH}$ were obtained for different mass flow rates, and it was concluded that the daily production rate increased from $28 \%$ to $141 \%$ and the thermal efficiency increased from $9 \%$ to $20 \%$ in the presence of the HDH system. A hybrid MSF-HDH 
desalination unit for energy recovery was studied by Lawal et al. [12]. The MSF-HDH unit increased the overall productivity and performance ratio and reduced brine rejection. Four different configurations of the MSF-HDH unit were proposed and compared. They revealed that the HDH system could use over $66 \%$ of an existing MSF brine. Additionally, the MSF-HDH unit had water recovery, productivity, a freshwater cost, and a gained output ratio (GOR) of $44.86 \%, 30,549 \mathrm{~m}^{3} /$ day, $1.068 \mathrm{USD} / \mathrm{m}^{3}$, and 8.73, respectively. An $\mathrm{HDH}$ system for desalination and space conditioning was investigated by Lawal et al. [13]. In their system feed water was heated using heat energy from a condenser and at the same time cooling water was cooled further inside the evaporator of the heat pump before it entered the dehumidifier. The air leaving the dehumidifier was traveling to the room for space conditioning. They revealed that the integrated system attained a GOR of 4.07 and the amount of water produced was $287.8 \mathrm{~L} /$ day. Additionally, the recovery ratio of the system was $4.86 \%$. The minimum specific energy consumption was $160.16 \mathrm{kWh} / \mathrm{m}^{3}$.

Another hybrid system, MD-HDH for zero liquid discharge (ZLD) for inland desalination was proposed by Matar et al. [14]. They found that HDH was effective in the generation of solids from the brine of the MD unit. A $40 \%$ recovery rate was produced by the MD producing the freshwater with TDS $<20 \mathrm{mg} / \mathrm{L}$ for a flux of $5 \mathrm{~L} / \mathrm{m}^{2} / \mathrm{h}$. HDH produced additional freshwater with TDS $<100 \mathrm{mg} / \mathrm{L}$. The energy required for the HDH and MD were $220 \mathrm{kWh} / \mathrm{m}^{3}$ and $260 \mathrm{kWh} / \mathrm{m}^{3}$, respectively.

The above literature showed that the integration of two or more desalination technologies had some additional benefits compared to a single desalting unit. Similarly, the hybrid CDI-HDH desalination system was proposed in this system and its explanation is as follows.

Capacitive deionization (CDI) is an advanced method for brackish/groundwater desalination in which water flows between a pair of biased/polarized electrodes. The anions and cations are attracted to the positive and negative electrodes, respectively. In CDI there are two modes of operation: ion adsorption and regeneration. During adsorption, the ions are removed from (treatable) feed water and attached to the electrodes. Regeneration is the reverse of the adsorption process: when the electrodes are saturated, the ions are removed from electrodes by reversing the current or making zero voltage. The water carries away ions during the regeneration mode and rejects it as wastewater, which is higher in salt concentration but still contains water. Treating wastewater is better than discarding it because every drop of water is highly precious. The drawbacks of the CDI process are: it cannot remove bacteria, viruses, or other poisoning materials such as boric acid (dangerous to human health and can cause nausea, vomiting, stomach aches, and diarrhea); and it cannot proceed with high-salinity water. The wastewater that leaves CDI cannot be re-treated using CDI. Proof of this is further explained in detail in Section 3.

Therefore, wastewater discarded from CDI can be treated in $\mathrm{HDH}$ desalination because of its ability to deal with water with a high salt concentration. HDH desalination is an emerging option in the desalination field, particularly for small-scale systems. HDH desalination technology mimics the rain cycle: in a humidifier, either air or water is heated; hot water is sprayed inside the evaporator (humidifier) over packing material; and air flows against the water flow and transports the water vapor at the expense of the heat of the water, leaving behind high-density salts. This hot, humid air is transferred to a dehumidifier, where cold water makes contact with the air and condenses it, thereby producing pure water. HDH desalination technology offers many advantages compared with other methods: it enables a stable and simple control system, does not require strict pretreatment, poses no scaling problem, enables operation at atmospheric pressure, is low maintenance, and has no sensitivity to water with a high salt concentration [15]. One of the major benefits of the HDH system is that it can be operated using any low-grade waste heat [16].

In this study, brackish water was treated inside the CDI unit, and wastewater leaving the CDI unit was further treated in the $\mathrm{HDH}$ desalination unit in order to recover more 
distillate water. Therefore, a theoretical study was carried out using the mathematical model of CDI and HDH desalination systems.

\section{System Description}

\subsection{System}

The CDI process involves the two main modes (adsorption and regeneration), as shown in Figure 1. In the following study, the CDI unit contains two stacks. If one stack is under regeneration, then the other stack performs purification [17], as shown in Figure 2.
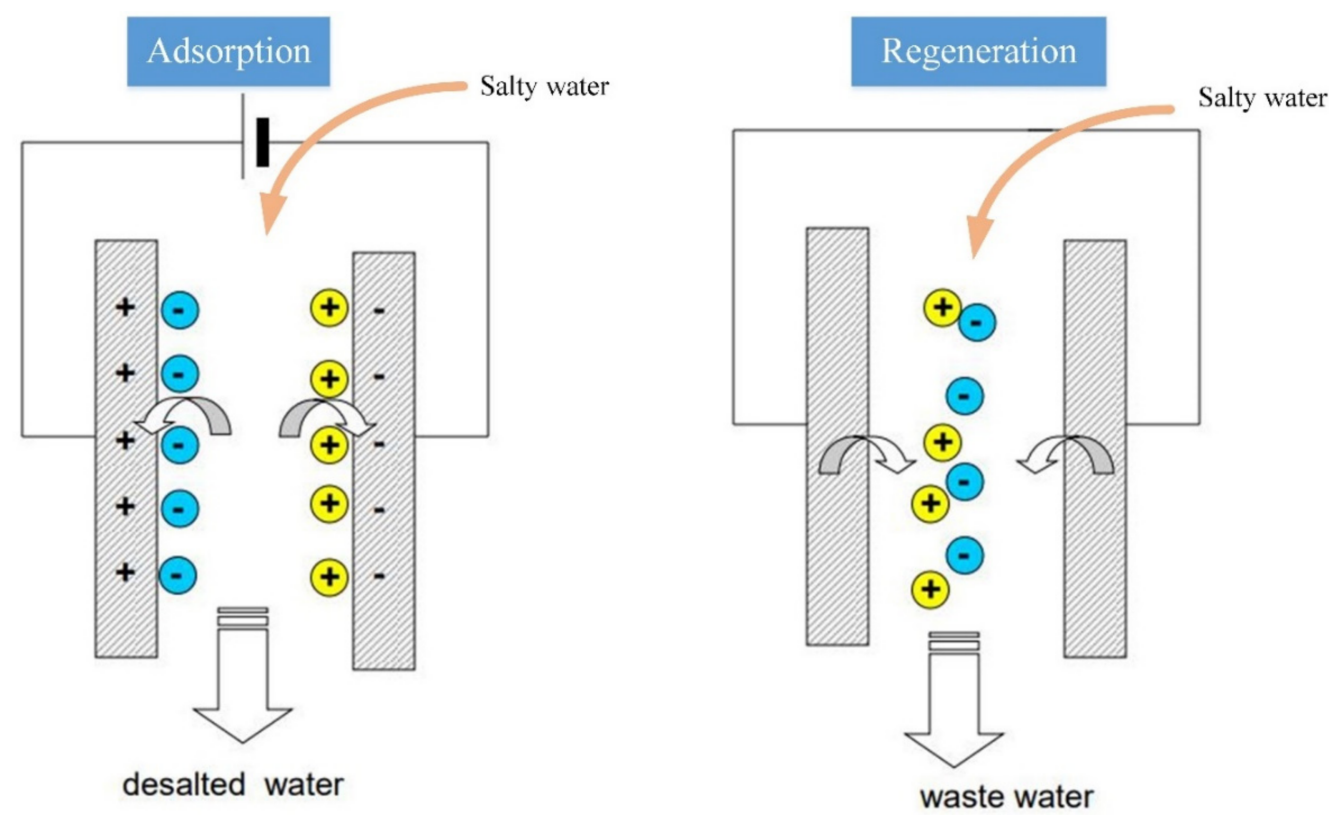

Figure 1. Two modes in the operation of CDI desalination.

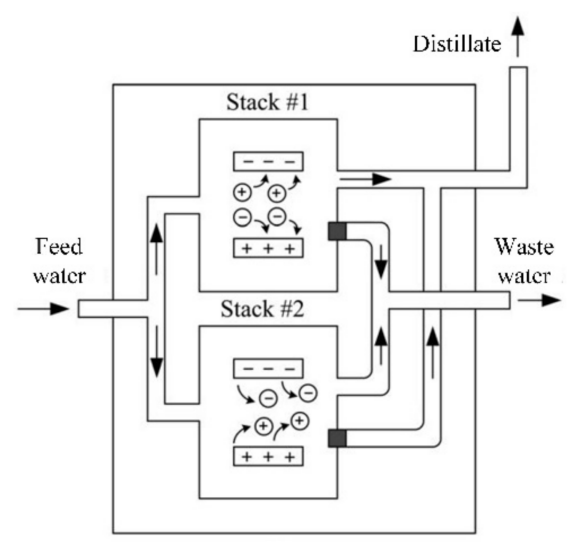

(a)

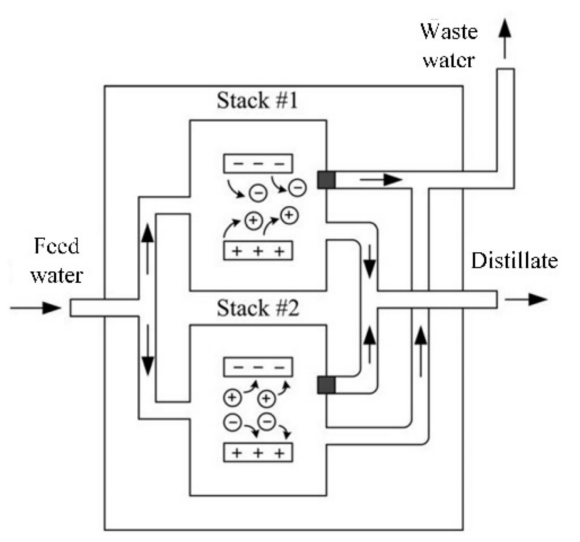

(b)

Figure 2. Working of two CDI stacks. (a) Stack \#1 is in adsorption mode and Stack \#2 is in regeneration mode. (b) Stack \#1 is in regeneration mode and Stack \#2 is in adsorption mode.

\subsection{Model}

The model developed by Jande and Kim [18] was used to compute the CDI system, and the CDI system was operated at a constant current. In this study, each stack contained 500 pairs of electrodes; each pair was assumed to have a capacitance $C_{a}$ of $8000 \mathrm{~F}$ (a reasonable amount for most activated carbon materials with a specific capacitance of at least $80 \mathrm{~F} / \mathrm{g}$, and $100 \mathrm{~g}$ is spread over $1 \mathrm{~m}^{2}$ ). The current $I$ to be used for water desalination for the specified CDI stack is expressed as shown in Equation (1), where $z$ is the average valence (for this study, only $\mathrm{NaCl}$ was being considered); $C_{f}$ is the feed water concentration 
in $\mathrm{mol} / \mathrm{m}^{3} ; F$ is the Faraday constant $(96,540 \mathrm{C} / \mathrm{mol}) ; \Phi$ is the feedwater flow rate to the CDI electrode pair; and $\lambda$ is the charge efficiency (assumed as one in this study, i.e., assuming that good materials or ion exchange membranes are used [17]).

$$
I=\frac{z C_{f} F \Phi}{\lambda}
$$

The CDI system under a constant current was charged for a duration $t_{c}$ based on Equation (2), where $V_{t}$ is the target voltage (which was $1.5 \mathrm{~V}$ for this study).

$$
t_{c}=\frac{C_{a} V_{t}}{I}
$$

During the charging time (water purification period by CDI), the amount of energy, $E$, stored for the entire stack is expressed as shown in Equation (3), where $C_{a}$ is the capacitance and $n$ is the number of electrode pairs for the stack, which was 500 for this study. For a CDI system, $83 \%$ of the stored energy can be recovered and used to operate the plant [17]. Therefore, only $17 \%$ of the stored energy was considered in this study as the energy used by the CDI system to produce freshwater.

$$
E=\frac{1}{2} n C_{a} V_{t}^{2}
$$

The total amount of freshwater produced during charging for the entire CDI stack cycle is the product of the flow rate to the system and the time used to charge the CDI stack. In this study, the charging time was considered to be equal to the discharging time; this implies that the cycle time for the CDI stack operation is twice the water purification time. It is important to note the specific energy consumption expressed in units of $\mathrm{kWh} / \mathrm{m}^{3}$, which implies the ratio of the energy used to produce fresh water to the amount of water produced, in the cycle time of the CDI operation. In this study, the spacer volume and dead volume were set as $20 \mathrm{~mL}$.

The brine concentration (effluent concentration during discharging, $C_{e f d}$ ) of the CDI electrode pair during constant-current discharging is constant, and it can be computed by determining the concentration at time $t=t_{c}$ using Equation (4) as described in [18], where $V_{c}$ is the dead volume. The brine salt concentration for the CDI stack is the same as the concentration from the electrode pair; however, the flow rate of the brine from the CDI stack is $\phi=n \Phi$ (which is equal to the flow rate during charging, where $\Phi$ is the flow rate to each pair of electrodes). The CDI stack wastewater with this concentration and flow rate is fed to the $\mathrm{HDH}$ system for purification, as will be described in the next section.

$$
C_{e f d}(t)=C_{f}+\frac{\lambda I}{z F \Phi}\left(1-e^{-\frac{\Phi}{V_{c}} t}\right)
$$

\subsection{HDH System}

The principle of the HDH system is simple: water evaporates inside the humidifier and the generated humid air is condensed inside the dehumidifier. The proposed HDH system is composed primarily of a humidifier, dehumidifier, and water heater. In the humidifier, the air is humidified through direct contact with the hot, salty water which is sprayed over the packing materials inside the humidifier; subsequently, the hot and humid air enters the dehumidifier and establishes contact with cold surfaces. The dehumidifier is a fin tube heat exchanger in which inlet water flows through tubes and air passes over fins. This causes the water vapor to condense from the air, thereby resulting in the production of distillate at the bottom of the dehumidifier. Air releases the enthalpy of condensation, which is recuperated and used to preheat the inlet water before it enters the heater. The water leaving the dehumidifier is then further heated up to the desired temperature. The air leaving the dehumidifier enters the humidifier for the next cycle. Meanwhile, the water leaving the humidifier has a higher salt concentration and is described as HDH brine. 


\subsection{HDH Model}

The thermodynamic model for a water-heated HDH system, as shown in Figure 3, is based on the energy and mass balance principle, and the following assumptions are considered:

- The system is in a steady state;

- Heat losses to the surroundings and conduction losses are disregarded;

- Kinetic and potential energy terms are disregarded;

- Pressure losses are disregarded;

- Pumping and fan powers are disregarded;

- Air is assumed to have $90 \%$ relative humidity at the humidifier and dehumidifier outlets [19];

- Humidifier outlet air and dehumidifier inlet air temperatures are assumed to be the same; similarly, the humidifier inlet air and dehumidifier outlet air temperatures are assumed to be the same [19];

- The water temperature at the dehumidifier inlet is assumed to be $25^{\circ} \mathrm{C}$;

- The effectiveness of the humidifier and dehumidifier was fixed at $85 \%$.

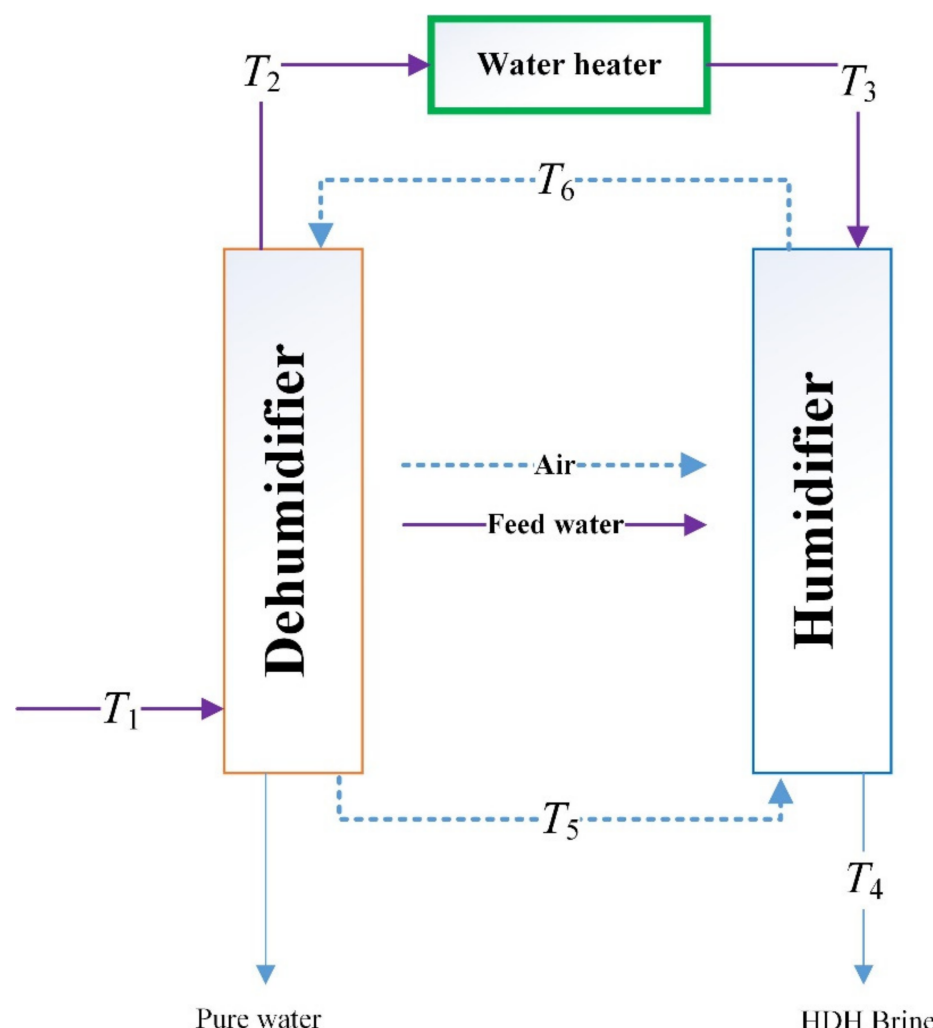

Figure 3. HDH desalination unit.

\subsubsection{Humidifier}

The energy balance equation for the humidifier is expressed as follows:

$$
\dot{m}_{w} H_{w 3}+\dot{m}_{a} H_{a 5}=\dot{m}_{b} H_{w 4}+\dot{m}_{a} H_{a 6}
$$

where $\dot{m}_{w}, \dot{m}_{a}$, and $\dot{m}_{b}$ are the mass flow rates of water, air, and brine, respectively; $H_{w 3}$ and $H_{w 4}$ are the enthalpies of water entering the humidifier and brine leaving the humidifier, respectively; and $H_{a 5}$ and $H_{a 6}$ are the enthalpies of air entering and leaving the humidifier, respectively; and $\dot{m}_{b}$ can be expressed as follows:

$$
\dot{m}_{b}=\dot{m}_{w}-\dot{m}_{a}\left(\omega_{6}-\omega_{5}\right)
$$


Equation (5) can be written as:

$$
\dot{m}_{w} H_{w 3}+\dot{m}_{a} H_{a 5}=\left[\dot{m}_{w}-\dot{m}_{a}\left(\omega_{6}-\omega_{5}\right)\right] H_{w 4}+\dot{m}_{a} H_{a 6}
$$

where $\omega_{6}$ and $\omega_{5}$ are the absolute humidity of air at the humidifier and dehumidifier outlet, respectively.

The effectiveness of the humidifier is expressed as [19]:

$$
\varepsilon_{h}=\max \left[\frac{H_{a 6}-H_{a 5}}{H_{a 6, \text { ideal }}-H_{a 5}}, \frac{H_{w 3}-H_{w 4}}{H_{w 3}-H_{w 4, \text { ideal }}}\right]
$$

where $H_{a 6, \text { ideal }}$ is the outlet air enthalpy measured at the temperature of the water at the humidifier inlet, and $H_{w 4, \text { ideal }}$ is the ideal enthalpy of the water measured at the temperature of the air at the humidifier inlet [20].

\subsubsection{Dehumidifier}

The energy balance in the dehumidifier is expressed as follows:

$$
\dot{m}_{w} H_{w 1}+\dot{m}_{a} H_{a 6}=\dot{m}_{w} H_{w 2}+\dot{m}_{a} H_{a 5}+\dot{m}_{d} H_{d}
$$

where $H_{w 1}$ is the enthalpy of the water entering the dehumidifier; $H_{w 2}$ is the enthalpy of the water leaving the dehumidifier; and $H_{d}$ is the enthalpy of the distillate at temperature $T_{d}$, which was set as the average of the air temperature at the inlet and outlet of the dehumidifier.

The distillate flow rate $\dot{m}_{d}$ is defined as follows:

$$
\dot{m}_{d}=\dot{m}_{a}\left(\omega_{6}-\omega_{5}\right)
$$

Equation (9) can be written as:

$$
\dot{m}_{w} H_{w 1}+\dot{m}_{a} H_{a 6}=\dot{m}_{w} H_{w 2}+\dot{m}_{a} H_{a 5}+\left[\dot{m}_{a}\left(\omega_{6}-\omega_{5}\right)\right] H_{d}
$$

where $\omega_{6}$ and $\omega_{5}$ are the humidity ratios of air at the dehumidifier inlet and outlet, respectively.

The effectiveness of the dehumidifier is expressed as [19]:

$$
\varepsilon_{d}=\max \left[\frac{H_{a 6}-H_{a 5}}{H_{a 6}-H_{a 5, i d e a l}}, \frac{H_{w 2}-H_{w 1}}{H_{w 2, \text { ideal }}-H_{w 1}}\right],
$$

where $H_{a 5, \text { ideal }}$ is the ideal enthalpy of air calculated at the temperature of the water at the dehumidifier inlet, and $H_{w 2, \text { ideal }}$ is the ideal enthalpy of water calculated at the temperature of the air at the dehumidifier inlet [20].

The enthalpy of saltwater is calculated as follows [21]:

$$
H_{w}=H_{p w}-S\left(\begin{array}{c}
a_{1}+a_{2} S+a_{3} S^{2}+a_{4} S^{3}+a_{5} T+a_{6} T^{2}+ \\
a_{7} T^{3}+a_{8} S T+a_{9} S^{2} T+a_{10} S T^{2}
\end{array}\right),
$$

where $S$ is the salt concentration, and the coefficients used in the equation above are listed in Table 1. $H_{p w}$ is the enthalpy of salt-free water, which is expressed as [21]:

$$
H_{p w}=141.355+4202.07 T-0.535 T^{2}+0.004 T^{3}
$$


Table 1. Coefficients used in Equation (13).

\begin{tabular}{cccc}
\hline$a_{1}$ & $-2.348 \times 10^{4}$ & $\mathrm{a}_{6}$ & -44.17 \\
$a_{2}$ & $3.15 \times 10^{5}$ & $\mathrm{a}_{7}$ & $2.139 \times 10^{-1}$ \\
$a_{3}$ & $2.803 \times 10^{6}$ & $\mathrm{a}_{8}$ & $-1.997 \times 10^{4}$ \\
$a_{4}$ & $-1.446 \times 10^{7}$ & $\mathrm{a}_{9}$ & $2.778 \times 10^{4}$ \\
$a_{5}$ & $7.826 \times 10^{3}$ & $\mathrm{a}_{10}$ & 97.28 \\
\hline
\end{tabular}

The enthalpy of moist air is expressed as [22]:

$$
H_{a}=\left(c_{p a}+c_{p v} \omega\right) T+h_{f g} \omega
$$

where $c_{p a}$ and $c_{p v}$ are the specific heat capacities of air and vapor, respectively, and $h_{f g}$ is the enthalpy of vaporization of water, whose expression over a temperature range of $5-200{ }^{\circ} \mathrm{C}$ is [23]:

$$
h_{f g}=\left(\begin{array}{c}
2501.897149-2.407064037 T+ \\
1.192217 \times 10^{-3} T^{2}-1.5863 \times 10^{-5} T^{3}
\end{array}\right)
$$

The humidity ratio is calculated as follows [24]:

$$
\omega=0.6219\left[\frac{\psi P_{S}}{P_{a t m}-\psi P_{S}}\right]
$$

where $\psi$ is the relative humidity, $P_{a t m}$ is the atmospheric pressure, and $P_{S}$ is the saturation pressure [25] expressed as:

$$
P_{S}=\left(\begin{array}{c}
2.7 \times 10^{-9} T^{5}+2.8 \times 10^{-7} T^{4}+ \\
2.7 \times 10^{-5} T^{3}+0.0014 T^{2}+ \\
0.044 T+0.61
\end{array}\right)
$$

\subsubsection{Heater}

The preheater is added to heat the water before the humidifier between points 2 and 3; therefore, a model for the input thermal energy is necessitated and is given as follows:

$$
\dot{Q}_{i n}=\dot{m}_{w} c_{p w}\left(T_{3}-T_{2}\right) \text {, }
$$

where $\dot{Q}_{i n}$ is the heat transfer rate required to raise the temperature of water from $T_{2}$ to $T_{3}$. The preheater energy may be provided by solar collectors, other forms of renewable energy, a process heating steam, a diesel engine, or low-grade energy available in industrial sites. The highly recommended option for supplying electricity and heat simultaneously to both the CDI and HDH units is further explained in Section 3.1.

The specific thermal energy consumption (STEC) is defined as follows [26]:

$$
S T E C=\frac{\dot{Q}_{i n} \rho}{3600 \dot{m}_{d}}
$$

where $\rho$ is water density.

The recovery ratio $(\mathrm{RR})$ is defined as the ratio of the distillate flow rate to the water flow rate, as follows [27]:

$$
R R=\frac{\dot{m}_{d}}{\dot{m}_{w}}
$$

Mass ratio is an important parameter in $\mathrm{HDH}$ desalination systems and is defined as follows:

$$
M R=\frac{\dot{m}_{w}}{\dot{m}_{a}}
$$


The salinity of the brine at the humidifier exit can be expressed in terms of the $R R$ as follows:

$$
S_{\text {out }}=\frac{S_{\text {in }}}{(1-R R)}
$$

where $S_{i n}$ is the salinity of the water at the humidifier inlet. The thermal performance of the $\mathrm{HDH}$ system is described in terms of the gained output ratio (GOR) which is calculated as follows [24]:

$$
G O R=\frac{\dot{m}_{d} h_{\mathrm{fg}}}{\dot{Q}_{\text {in }}}
$$

where $h_{\mathrm{fg}}$ is the latent heat of the vaporization of water.

The objective of the HDH model is to predict the system performance, which is expressed in terms of the distilled water flow rate, recovery ratio, and energy required. The evaluation of the distilled water flow rate requires the calculation of temperatures $T_{5}$ and $T_{6}$; the recovery ratio can be calculated after determining the distillate rate. To determine the energy required, temperature $T_{2}$ must be calculated, as shown in Equation (19). Therefore, the unknowns are $T_{2}, T_{4}, T_{5}, T_{6}$, and $\dot{Q}_{i n}$, and the five associated equations are Equations (7), (8), (11), (12) and (19). The equations are nonlinear and were solved using the Newton-Raphson method, and the code was built using MATLAB software. The known parameters were air and water flow rates, inlet salinities and temperatures at the dehumidifier and humidifier, the effectiveness of the humidifier and dehumidifier, the relative humidity of the air, and the specific heat capacities of water and air.

\subsection{CDI-HDH System}

The schematic illustration presented in Figure 4 shows the hybrid CDI-HDH system. The system comprises a CDI unit, buffer tank, and HDH unit. The brackish water enters the CDI unit and is treated to extract freshwater. After treatment, the CDI brine is stored in a buffer and subsequently fed into a water-heated $\mathrm{HDH}$ unit at room temperature for further treatment.

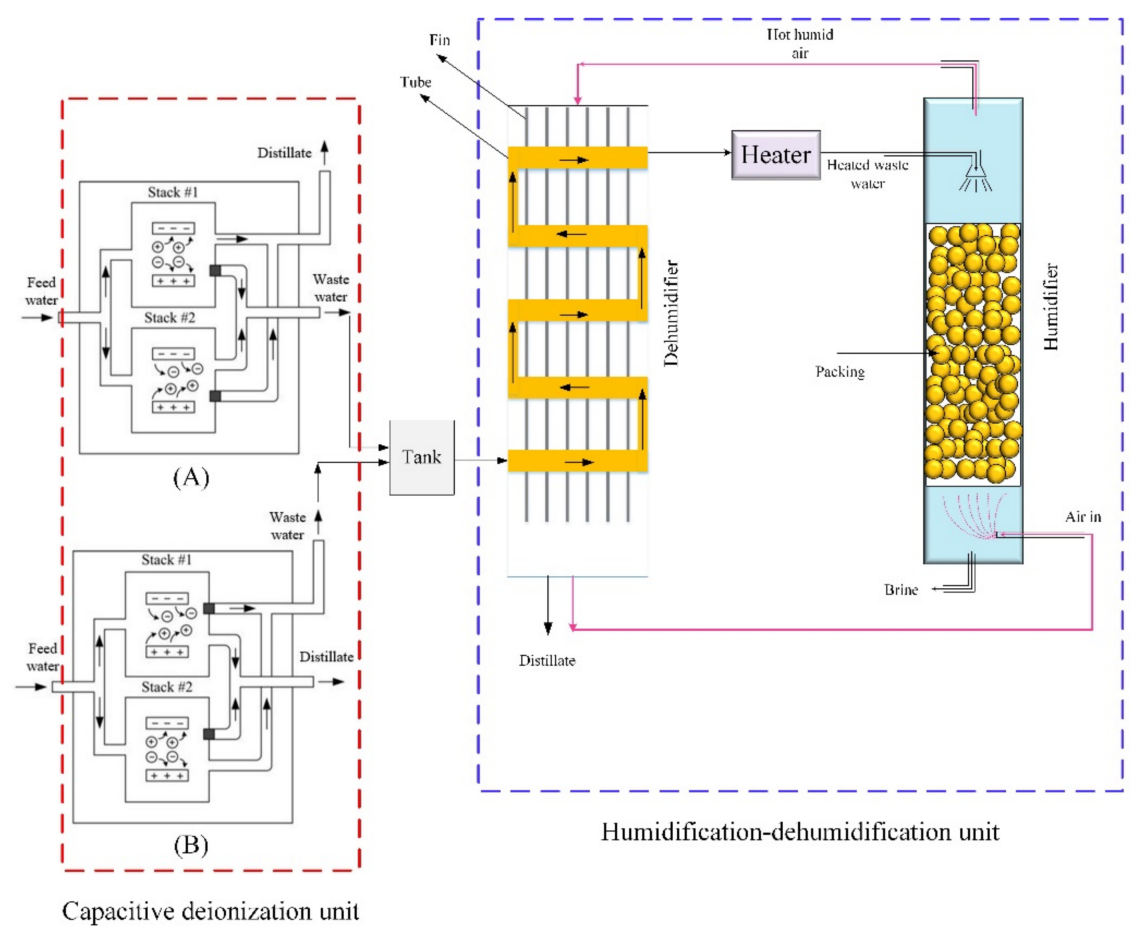

Figure 4. Schematic illustration of hybrid CDI-HDH system for brackish water desalination. Within CDI unit (A) Stack \#1 is in adsorption mode and Stack \#2 is in regeneration mode. (B) Stack \#1 is in regeneration mode and Stack \#2 is in adsorption mode. 


\section{Results and Discussion}

Five different cases of CDI inlet feed flow rates and salinities were considered for analysis, as shown in Table 2. The salinities of feedwater at the inlet were selected considering the fact that brackish water salinity ranges from 1500 to 15,000 ppm [28]. For each case of the CDI unit, the productivity, cycle time, purity of distilled water, and energy consumption were determined, as shown in Table 3.

Table 2. Different CDI inlet feed conditions for analysis in this study.

\begin{tabular}{ccc}
\hline Case No. & Feed Salinity $(\mathrm{ppm})$ & Flow Rate $(\mathrm{L} / \mathbf{s})$ \\
\hline 1 & 11,038 & 0.0147 \\
2 & 8729 & 0.0167 \\
3 & 8331 & 0.0197 \\
4 & 8109 & 0.0217 \\
5 & 9934 & 0.0227 \\
\hline
\end{tabular}

Table 3. CDI output: productivity, purity, cycle time, specific energy consumption, and wastewater salinity for five cases of feed water.

\begin{tabular}{cccccc}
\hline $\begin{array}{c}\text { Case } \\
\text { No. }\end{array}$ & $\begin{array}{c}\text { Amount of Water } \\
\text { Produced in One } \\
\text { CYCLE (L) }\end{array}$ & $\begin{array}{c}\text { Cycle Time } \\
\text { (h) }\end{array}$ & $\begin{array}{c}\text { Purity of } \\
\text { Distilled } \\
\text { Water (ppm) }\end{array}$ & $\begin{array}{c}\text { Specific Energy } \\
\text { Consumption } \\
\text { (kWh/m3) }\end{array}$ & $\begin{array}{c}\text { Wastewater } \\
\text { Salinity } \\
\text { (ppm) }\end{array}$ \\
\hline 1 & 329.4 & 12.4 & 335 & 0.65 & 22,078 \\
2 & 416.5 & 13.8 & 210 & 0.51 & 17,456 \\
3 & 436.4 & 12.3 & 191 & 0.49 & 16,661 \\
4 & 448.4 & 11.4 & 181 & 0.47 & 16,216 \\
5 & 366.0 & 8.9 & 271 & 0.58 & 19,867 \\
\hline
\end{tabular}

The results in Table 3 illustrate the reason that CDI cannot work with higher feed concentrations: an increase in the feedwater salinity increases the specific energy consumption (SEC), reduces the distillate water purity, and reduces the production of distillate. In Case 1, when the highest feed salinity is considered, i.e., $11,038 \mathrm{ppm}$, the energy consumption is also highest at $0.65 \mathrm{kWh} / \mathrm{m}^{3}$ and the purity of the distilled water is also reduced; in other words, the salinity of the distillate water is increased. Additionally, the amount of water produced is lower, at $329.4 \mathrm{~L}$ per cycle.

As the salinity decreased in Cases 2,3, and 4, it can be seen that the SEC also decreased to $0.51,0.49$, and $0.47 \mathrm{kWh} / \mathrm{m}^{3}$, respectively; the purity of the distilled water increased to 210,191 , and $181 \mathrm{ppm}$, respectively; and the amount of water produced increased to $416.5,436.4$ and $448.4 \mathrm{~L}$ per cycle, respectively. For Case 5, when the salinity was again increased, the results showed that the SEC increased to $0.58 \mathrm{kWh} / \mathrm{m}^{3}$, the purity decreased to $271 \mathrm{ppm}$, and the amount of water produced was $366 \mathrm{~L}$. It can also be seen that an increase in the feedwater salinity increases the salinity of the wastewater and distillate; therefore, CDI operation at higher salinities is not favorable because it will not produce distillate within a potable range.

The wastewater from the CDI unit had a higher salinity that was beyond the operating limit of CDI [29] and therefore this wastewater was treated inside the HDH desalination unit. The wastewater leaving the CDI unit during the regeneration process is fed into the $\mathrm{HDH}$ unit at a dehumidifier inlet at room temperature at $25^{\circ} \mathrm{C}$. Since the mass flow rate of wastewater cannot be changed in the $\mathrm{HDH}$, the only parameters that can be altered inside the $\mathrm{HDH}$ unit are mass ratio (MR), which is the ratio of water mass flow rate to the air mass flow rate defined by Equation (22), and the humidifier inlet water temperature $T_{3}$, which is the wastewater temperature at the humidifier inlet. To evaluate the system performance of the HDH unit, the mass ratios (MRs) from one to six were considered. This range was considered in order to find out the optimal MR, keeping in mind that the MR should be more than or equal to one for balanced conditions [30]. The air flow rate in the 
MR was changing but the feed water flow rate was kept constant. The humidifier inlet water temperature $T_{3}$ was selected to be $50-80{ }^{\circ} \mathrm{C}$ because this operating range is preferred, provided that a heat source is available and materials are durable [31].

The effect of the MR on HDH performance was investigated. The MR was set from one to six, and the distillate production rate from the HDH unit vs. the MR is shown in Figure 5. The results showed that the distillate production rate for all cases of wastewater increased with an increase in the MR up to three, and the distillate production rate decreased after that with a further increase in the MR. This is because for an MR of three, the contact time between the air and water increases, and the air carries away more moisture from the humidifier, but the larger the MR, the shorter the residence time, and the air is discharged from the humidifier without getting enough moisture. The productivity was the lowest at an MR of six in all cases.

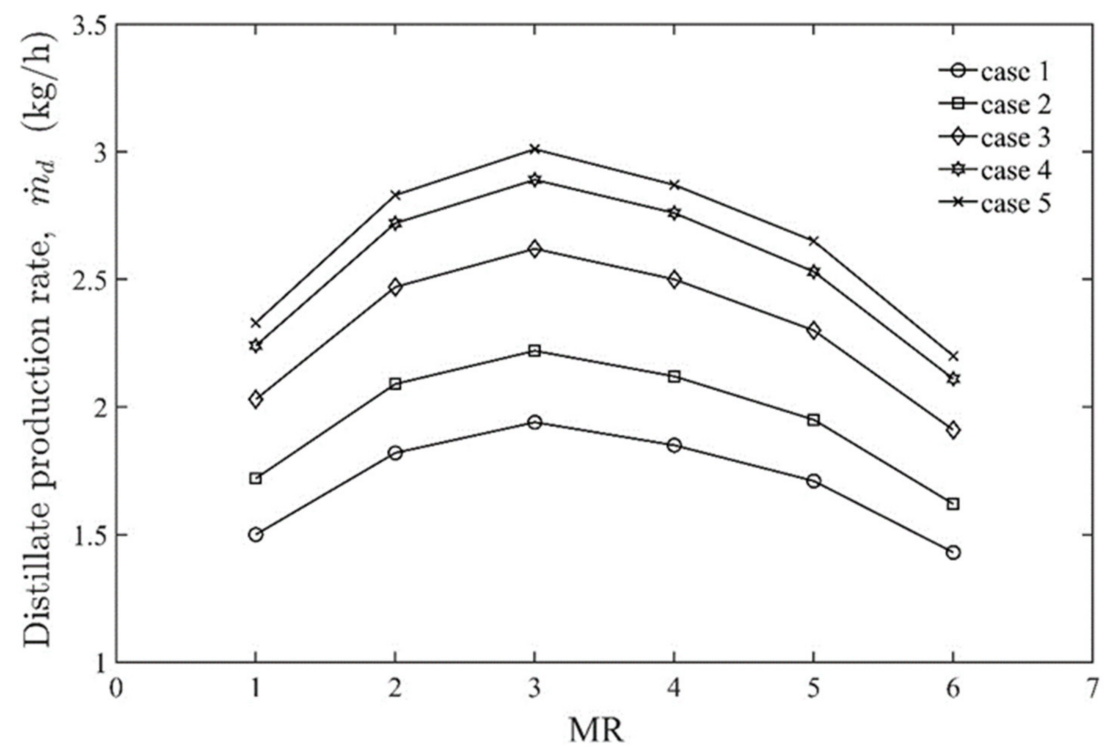

Figure 5. Distilled water flow rate variation with different MRs for all cases of CDI brine.

Figure 6 shows that at $\mathrm{MR}=3$, the salinity of the $\mathrm{HDH}$ brine was higher at higher flow rates (Case 1) because higher evaporation occurred at this MR, leading to more concentrated brine exiting the humidifier, while at a higher MR less evaporation occurred, which results in brine exiting with a lower salt concentration.

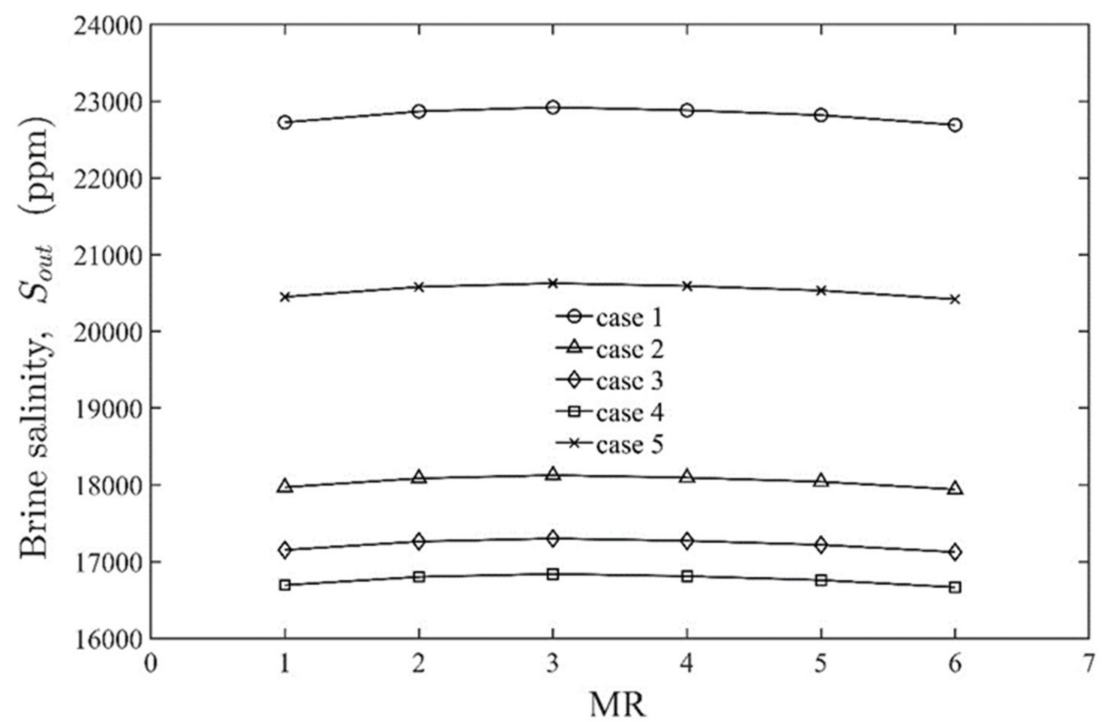

Figure 6. HDH brine salinity for different MRs. 
Figure 7 shows the variation in the moisture content (humidity ratio of the air) with an increase in the MR for all five cases. The results indicated that the humidity ratio of the air across the humidifier outlet was highest in Case 5 with an MR of three and lowest in Case 1 with an MR of six.

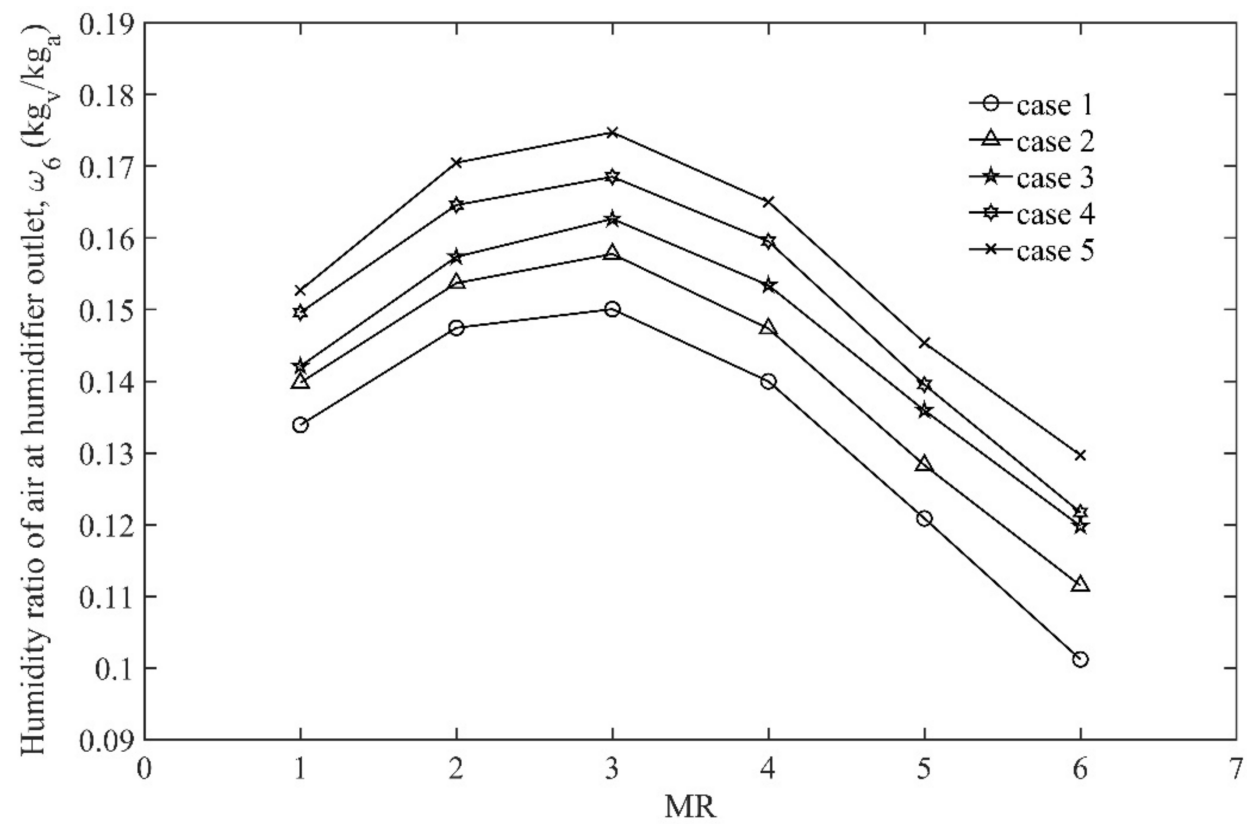

Figure 7. Humidity ratio of air across humidifier outlet for different MRs with relatable 90.

The effect of the humidifier inlet water temperature on the specific thermal energy consumption rate (STEC) is depicted in Figure 8. It can be seen that at higher values of $T_{3}$ energy consumption was lower while at lower values of $T_{3}$ the STEC was very high.

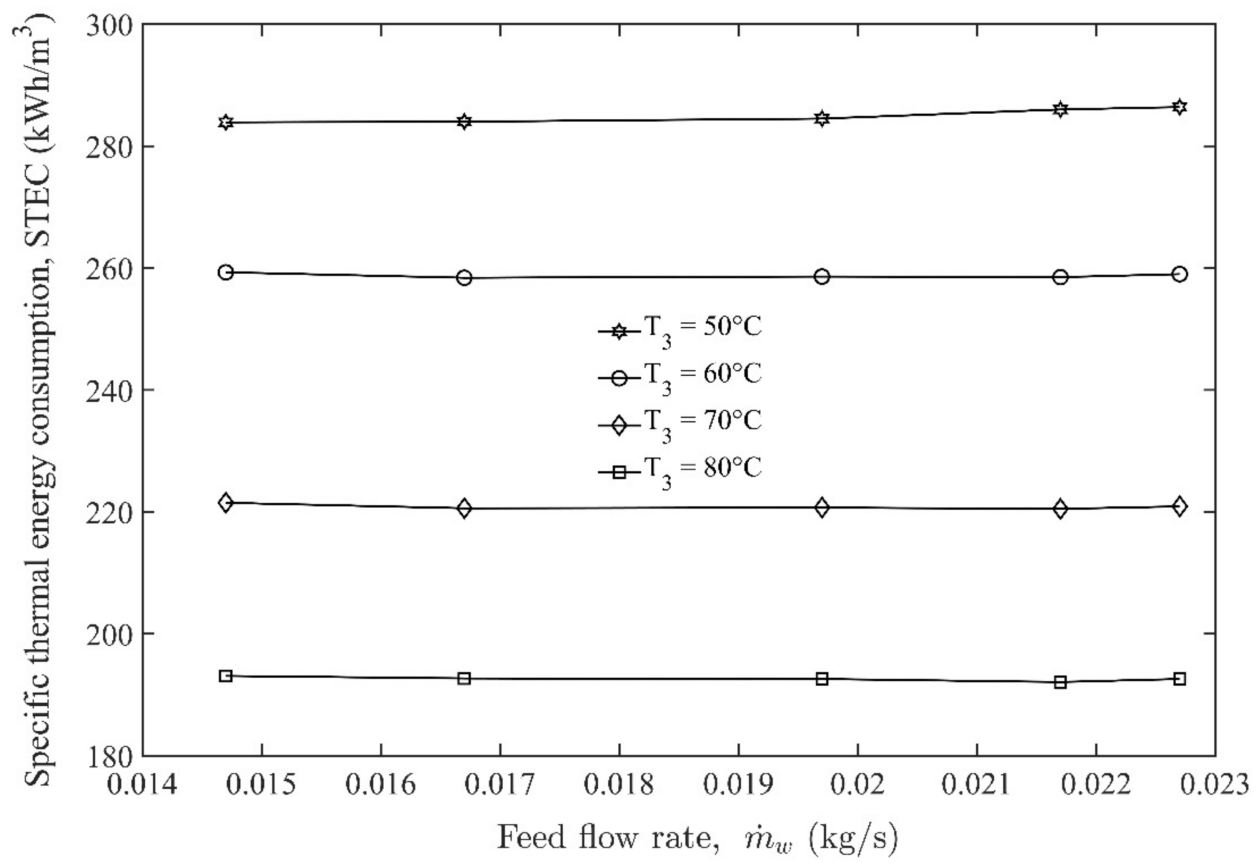

Figure 8. Specific thermal energy consumption in $\mathrm{HDH}$ at different feed water temperatures at humidifier inlet. 
The effect of the humidifier inlet water temperature $T_{3}$ on the distillate production rate is shown in Figure 9. It can be seen that the highest distillate production rate $(3.83 \mathrm{~kg} / \mathrm{h})$ was recorded at the higher humidifier inlet water temperature and higher CDI brine flow rate at the dehumidifier, i.e., $80{ }^{\circ} \mathrm{C}$ and $0.0227 \mathrm{~kg} / \mathrm{s}$, respectively. This is because at a higher humidifier inlet water temperature, the evaporation rate is also higher. At a higher feedwater flow rate $(0.0227 \mathrm{~kg} / \mathrm{s})$, the distillate production rate also increases because the surface temperature of the dehumidifier is reduced and causes more condensation, which in turn collects more distillate at the dehumidifier bottom.

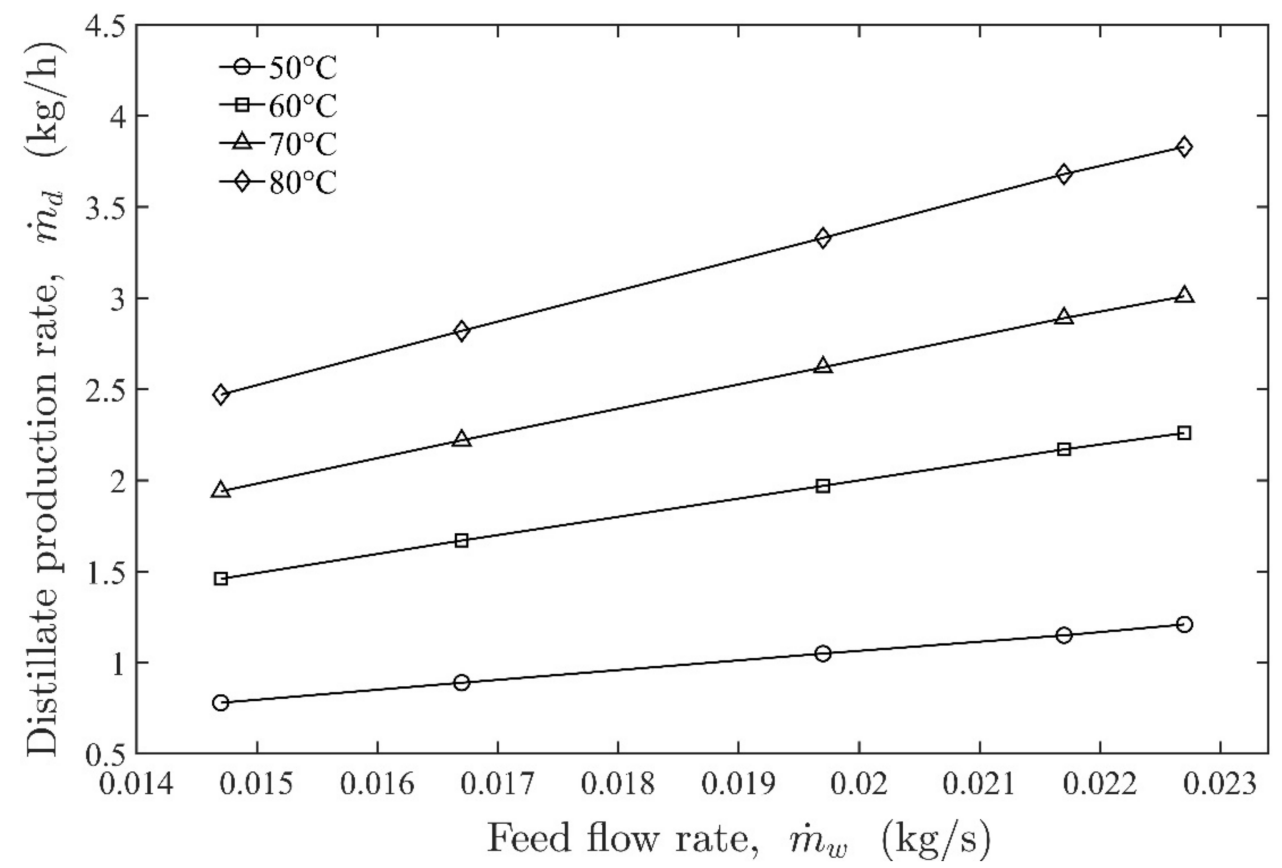

Figure 9. Distilled water flow rates vs. CDI brine flow rate at dehumidifier inlet for different humidifier inlet water temperatures in $\mathrm{HDH}$ with $\mathrm{MR}=3$ for all five cases of feedwater flow rate.

Figure 10 shows the effect of humidifier inlet water temperature on outlet brine salinity from $\mathrm{HDH}$. It was observed that at higher humidifier inlet water temperatures the brine salinities were also higher. This is because at a higher humidifier inlet water temperature, evaporation is higher, and this leads to more concentrated brine exiting the humidifier. At $80^{\circ} \mathrm{C}$, the salinity of the $\mathrm{HDH}$ brine was higher, with a concentration of about $30,000 \mathrm{ppm}$. Figure 11 shows the effect of the humidifier inlet water temperature on the recovery ratio (RR) from HDH. It was observed that at higher humidifier inlet water temperatures the $R R$ was higher. This is because at higher humidifier inlet water temperatures, the distillate production rate was also higher. The $R R$ was $3.92 \%, 7.54 \%, 13.71 \%$, and $24.90 \%$ at $50{ }^{\circ} \mathrm{C}$, $60{ }^{\circ} \mathrm{C}, 70^{\circ} \mathrm{C}$, and $80^{\circ} \mathrm{C}$, respectively, for a wastewater salinity of $22,078 \mathrm{ppm}$.

The combined distillate production rate of the CDI-HDH system per day for all cases is shown in Figure 12. The highest production rate was approximately $1079 \mathrm{~L} /$ day for Case 5 $\left(\dot{m}_{s w}=0.0227 \mathrm{~kg} / \mathrm{s}\right.$, feed salinity $\left.19,867 \mathrm{ppm}\right)$, and the lowest rate was approximately $697 \mathrm{~L} /$ day for Case 1 ( $\dot{m}_{s w}=0.0147 \mathrm{~kg} / \mathrm{s}$, feed salinity 22,078 ppm). The results shown in Figure 11 were obtained based on the following $\mathrm{HDH}$ conditions: $\mathrm{MR}=3.0$; component effectiveness $=80 \%$; humidifier inlet water temperature $=80^{\circ} \mathrm{C}$.

Figure 13 demonstrates the results of the present $\mathrm{HDH}$ model and that of Narayen et al. [30]. The variation of the GOR (defined by Equation (24)) versus the MR for the humidifier effectiveness $\left(\varepsilon_{h}\right)$ of the different systems was determined. The MR is the ratio of the seawater mass flow rate to the air mass flow rate. The operating conditions were $T_{\min }=30^{\circ} \mathrm{C}$, $T_{\text {top }}=80^{\circ} \mathrm{C}$, and $\varepsilon_{d}=80 \%$, where $T_{\min }$ denotes the seawater temperature at the dehumidifier inlet and $T_{\text {top }}$ is the seawater temperature at the inlet of the humidifier. The acceptable 
accuracy was achieved between the current model and Narayen et al. [30] with a deviation percentage of about $3.87 \%$.

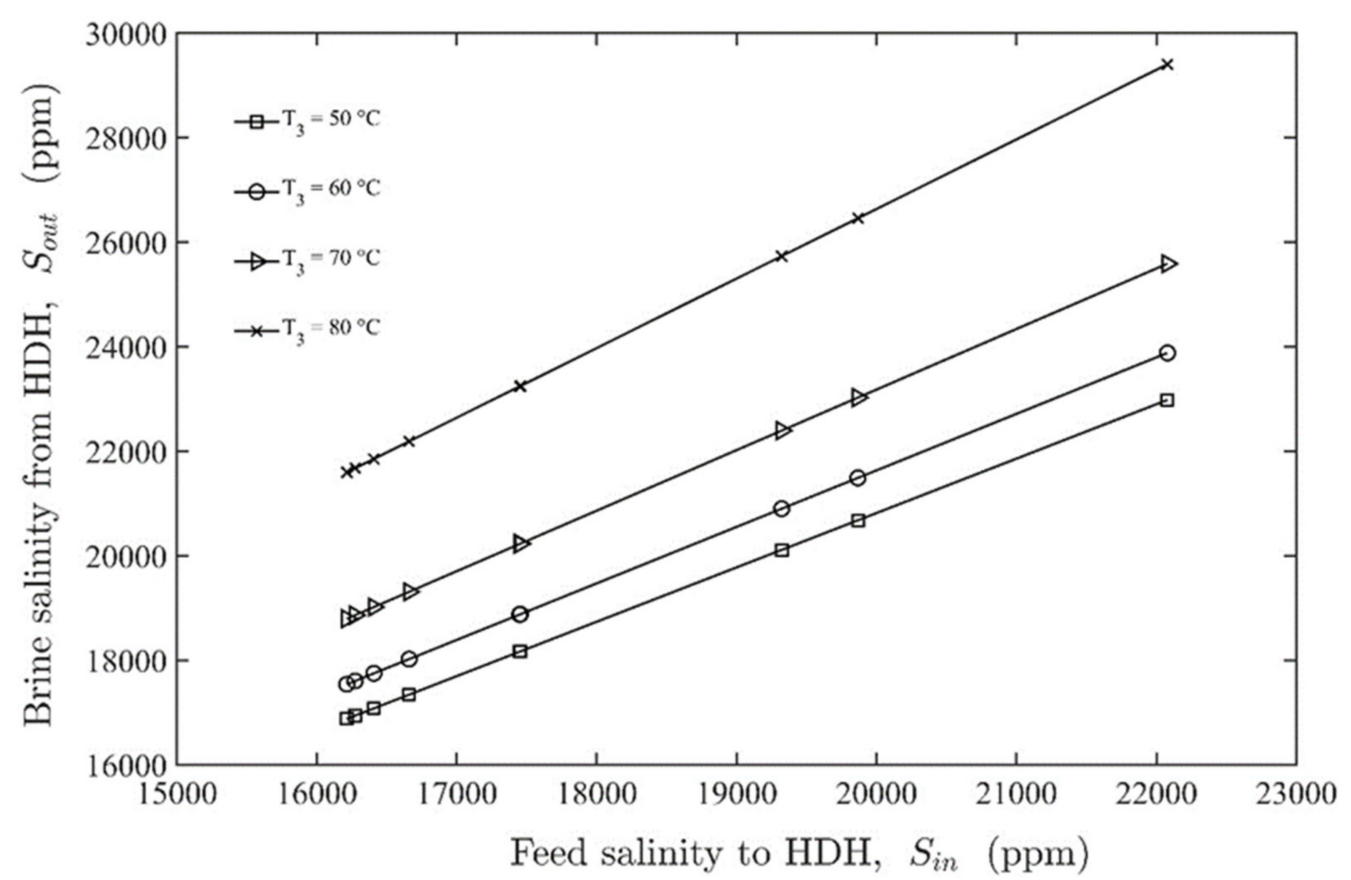

Figure 10. HDH brine salinity vs. CDI brine flow rate at dehumidifier inlet for different humidifier inlet water temperatures in $\mathrm{HDH}$ with $\mathrm{MR}=3$.

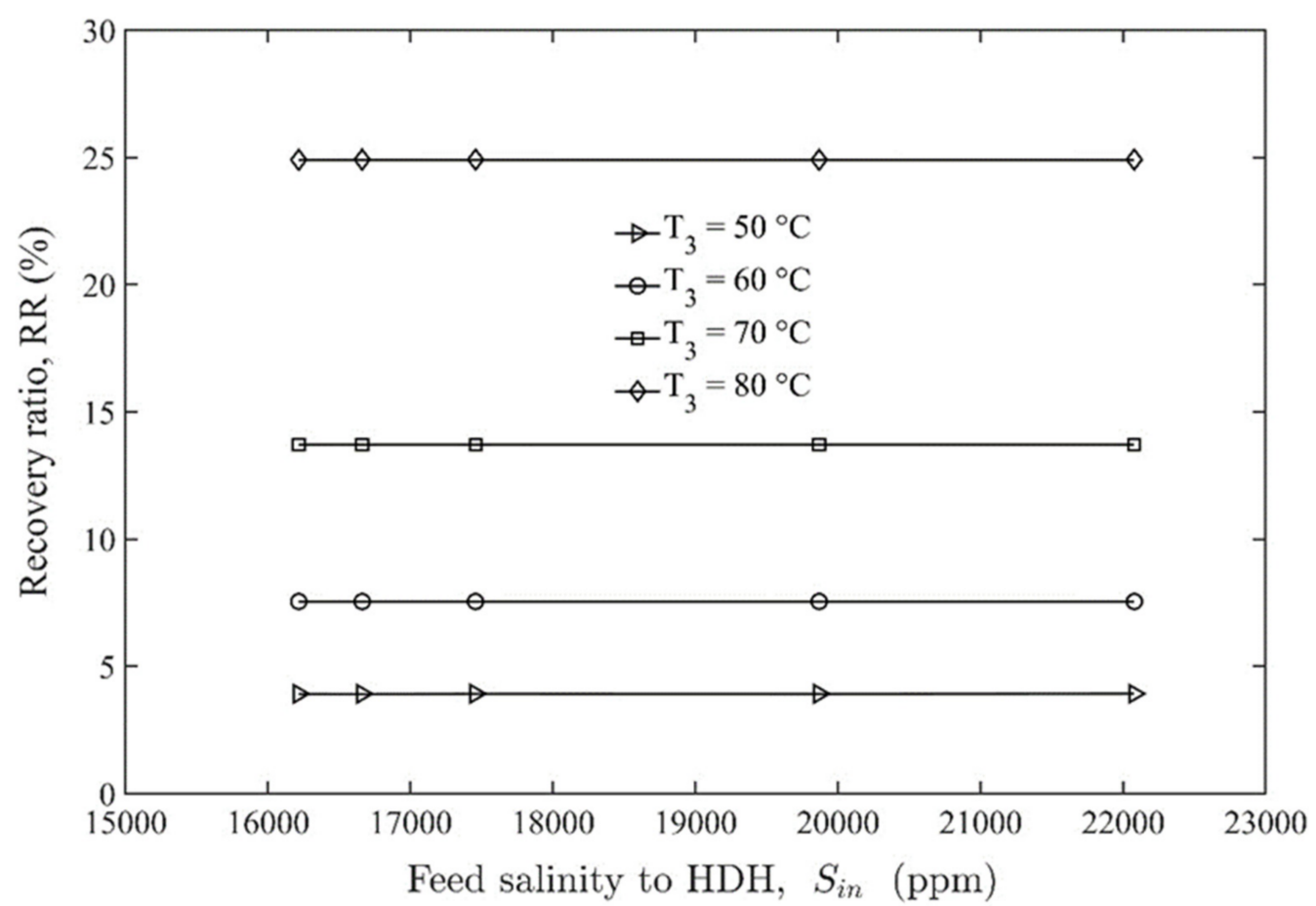

Figure 11. Recovery ratio from $\mathrm{HDH}$ unit at different humidifier inlet water temperatures. 


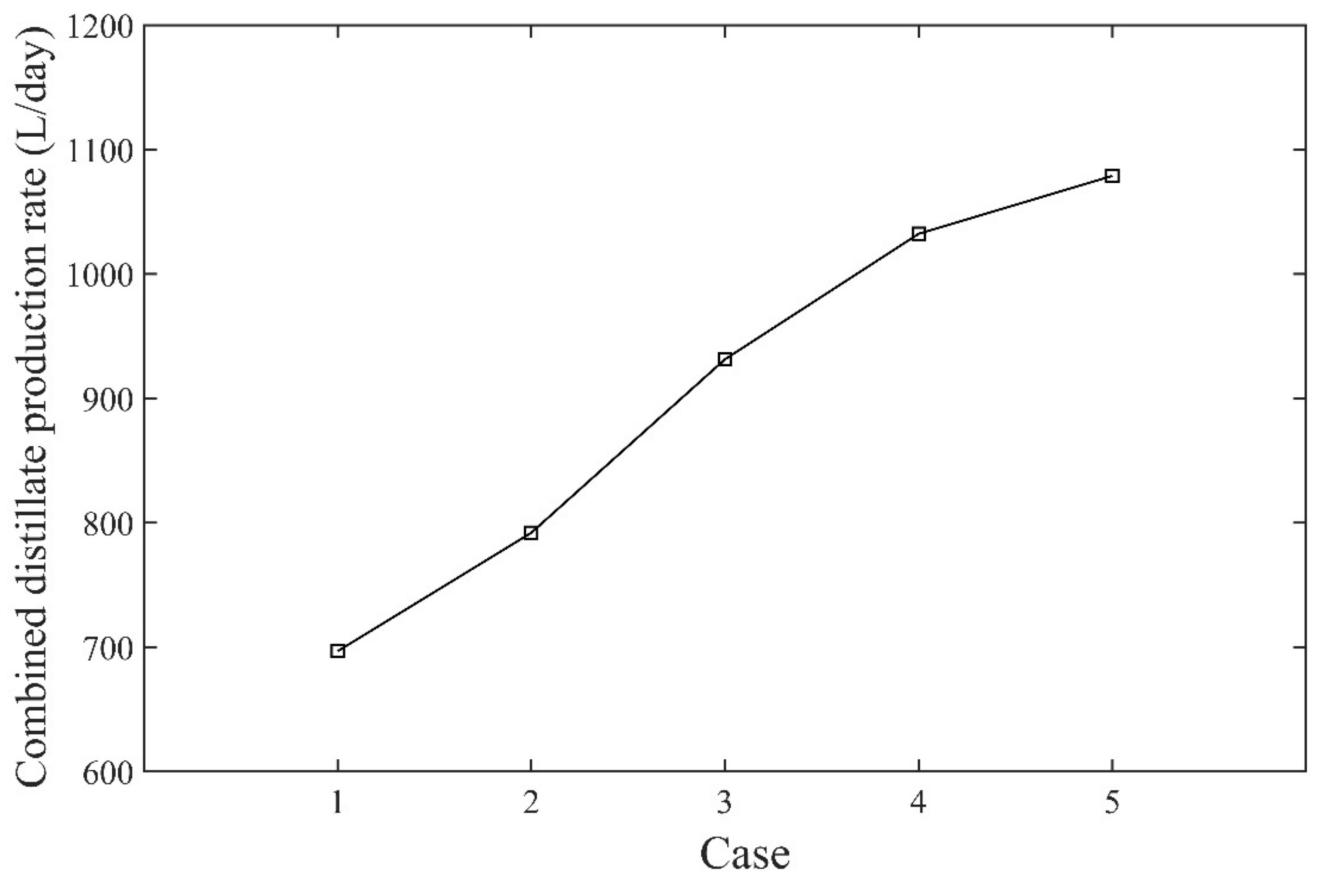

Figure 12. Combined distillate production rate of CDI-HDH system for all five cases.

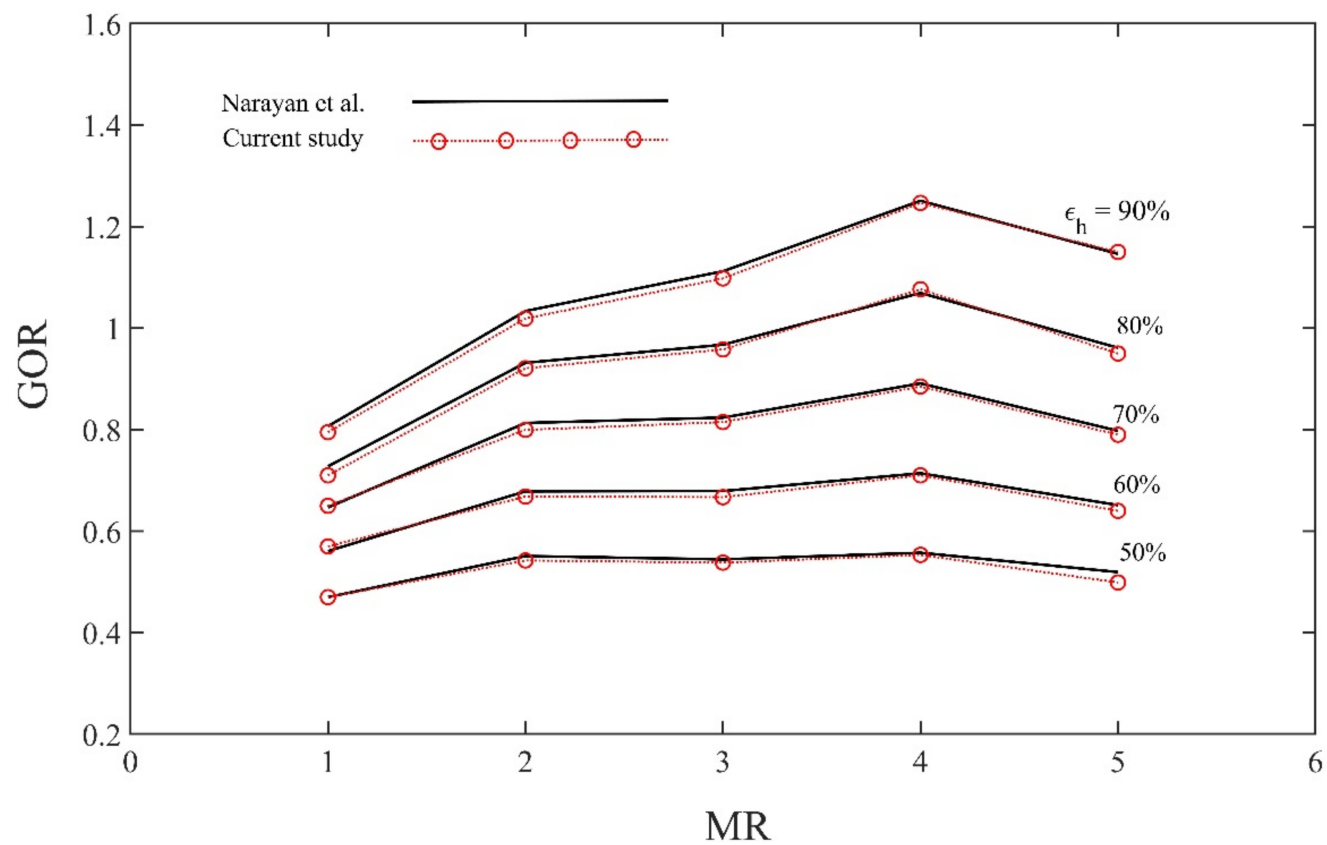

Figure 13. Comparison of current HDH model with Narayan et al. [30].

\subsection{Recommended Energy Options to Operate the CDI-HDH}

The CDI process has a lower energy consumption than $\mathrm{HDH}$, which is a highly energy consuming process because of the higher specific heat capacity of water. Thus, choosing an appropriate environmentally friendly energy source, such as one that does not release $\mathrm{CO}_{2}$ emissions, is crucial. Therefore, two exceptional renewable energy sources for electrical energy and waste heat of renewable energy-based technologies were suggested for the operation of the CDI-HDH hybrid system.

The first one is a photovoltaic thermal (PVT) panel; PVT panels convert solar radiation into electrical and thermal energy. While PV cells convert light energy into electrical energy, the cells get heated; therefore, cooling the cells is important for improving their efficiency and saving them from damage. PVT panels are divided into two main types: PVT liquid 
type and PVT air collector. Either of these types is useful in the operation of an HDH system because the HDH system may be either a water-heated or air-heated system. Therefore, electrical energy will be used for operating the CDI unit while thermal energy is used to heat air/water in the HDH unit as shown in Figure 14. The second recommended option is wind energy, converted into electrical energy, that would be used for the operation of the CDI unit. Thermal energy can be extracted while cooling the wind turbine generator (cooling is necessary to ensure the longevity of the turbine), and this thermal energy can be used in the HDH unit as shown in Figure 15.

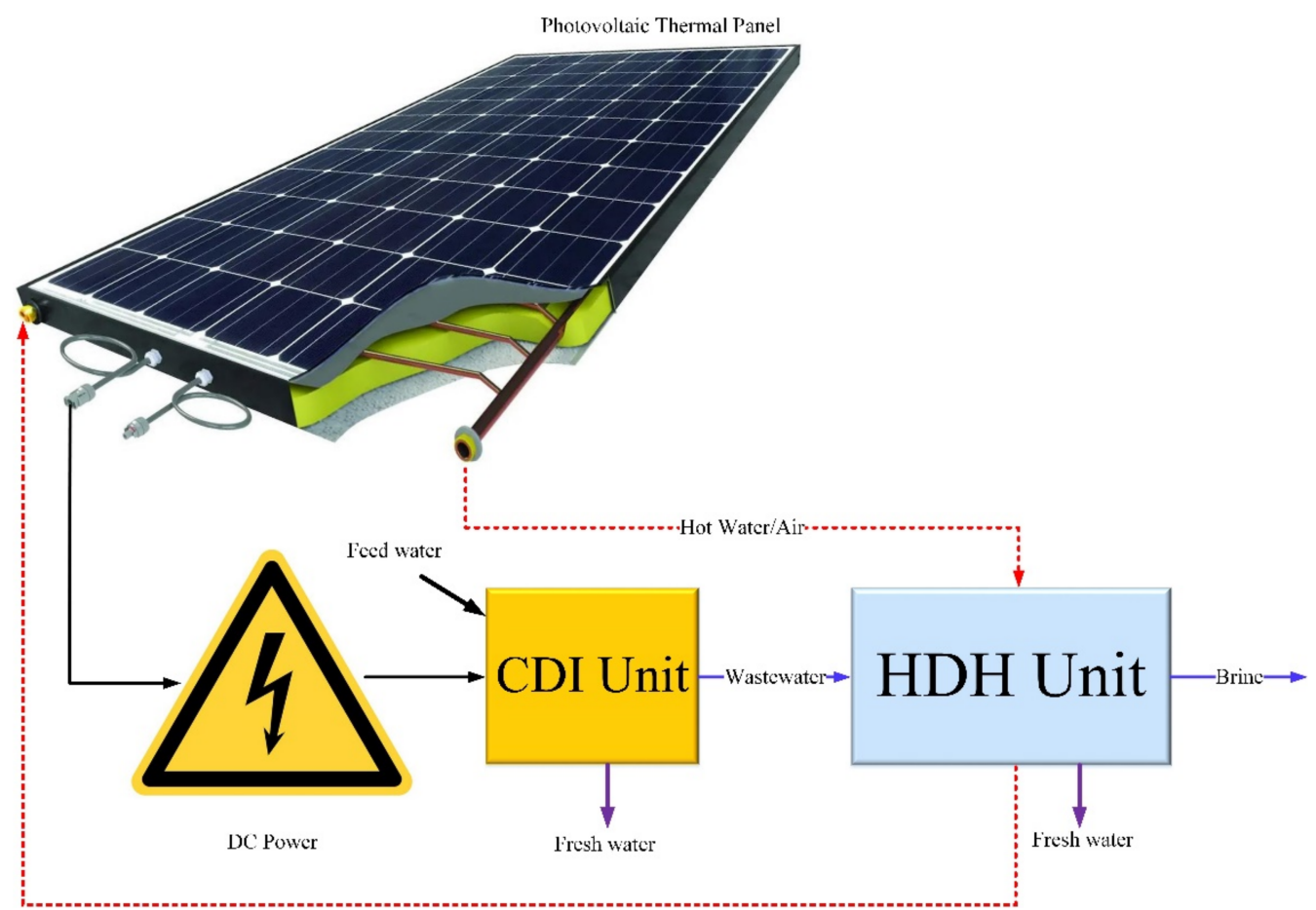

Figure 14. Schematic of PVT-driven CDI-HDH desalination system.

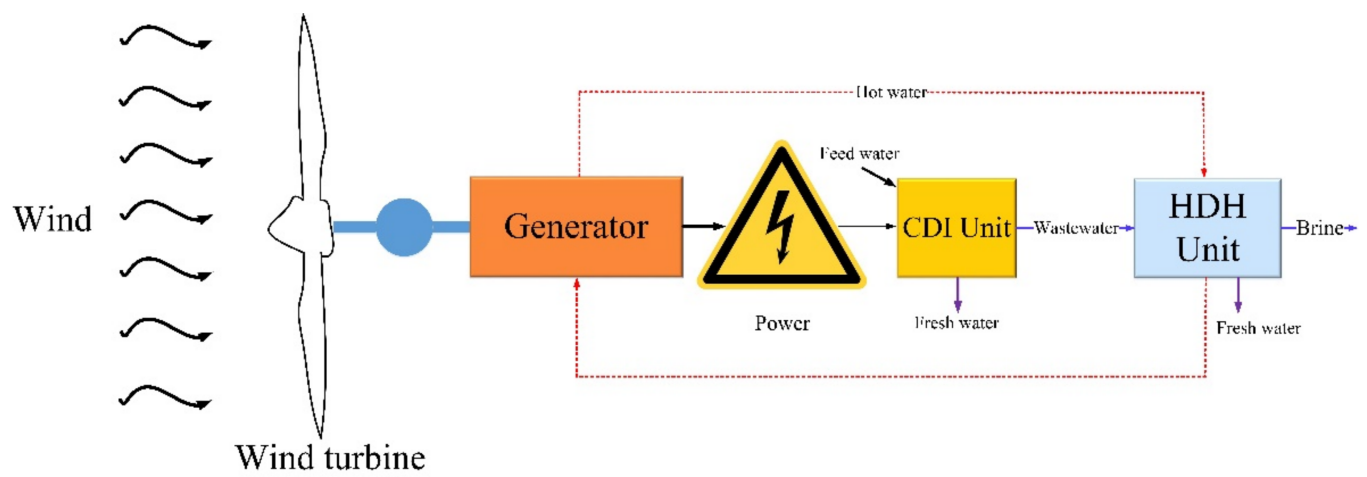

Figure 15. Schematic of wind energy-driven CDI-HDH desalination system.

\section{Conclusions}

This paper theoretically examined the hybridization of CDI and HDH for brackish water desalination using mathematical models of CDI and HDH desalination technologies. The wastewater leaving the CDI unit during the regeneration process still had a significant water content. Instead of discharging this wastewater, it can be further treated to produce distillate by using the waste heat that would instead be dissipated into the environment. Therefore, a CDI-HDH system was created, the wastewater from CDI was treated using $\mathrm{HDH}$, and the effects of different flow rates and salinities for brackish water at the inlet of the CDI unit were analyzed. With an increase in feed water salinity, the specific energy con- 
sumption (SEC) of CDI increases, the purity of distillate decreases, and the amount of water produced decreases. This study concluded that using the CDI unit with water containing a higher salt concentration was not a favorable process, while $\mathrm{HDH}$ is highly workable for any level of salinity and therefore worked well with CDI wastewater processing.

It was discovered that the amount of water produced from CDI in $11.4 \mathrm{~h}$ (for Case 4 ) was approximately $448 \mathrm{~L}$. Additionally, when the HDH system was operated for the same number of hours, approximately $34 \mathrm{~L}$ of water was produced. Therefore, the combined productivity from the CDI-HDH combined system from $11.4 \mathrm{~h}$ of operation was higher than that of the CDI unit alone (i.e., approximately $482 \mathrm{~L}$ ). In addition, the maximum daily total distillation rate was approximately $1079 \mathrm{~L} /$ day for Case 5 conditions. The highest recovery rate achieved was $24.90 \%$ from the $\mathrm{HDH}$ unit at a humidifier inlet water temperature of $80^{\circ} \mathrm{C}$. Additionally, two renewable energy sources were recommended to operate the CDI-HDH system: one using PVT and the other using wind energy. These recommendations were accompanied by a detailed schematic.

Author Contributions: Conceptualization, S.-H.S., Y.A.C.J. and Y.-D.K.; methodology, S.-H.S. and Y.A.C.J.; writing - original draft preparation, S.-H.S., Y.A.C.J., S.M., W.-S.K. and Y.-D.K.; writingreview and editing, S.-H.S., Y.A.C.J. and Y.-D.K.; supervision, Y.-D.K. and W.-S.K.; project adminstartion, Y.-D.K. and W.-S.K.; funding acquisition, Y.-D.K. and W.-S.K. All authors have read and agreed to the published version of the manuscript.

Funding: This research was funded by Korea Institute of Energy Technology Evaluation and Planning (KETEP) Ministry of Trade, Industry, and Energy (MOTIE) of Republic of Korea, 20194010201740.

Institutional Review Board Statement: Not applicable.

Informed Consent Statement: Not applicable.

Data Availability Statement: Not applicable.

Conflicts of Interest: The authors declare no conflict of interest.

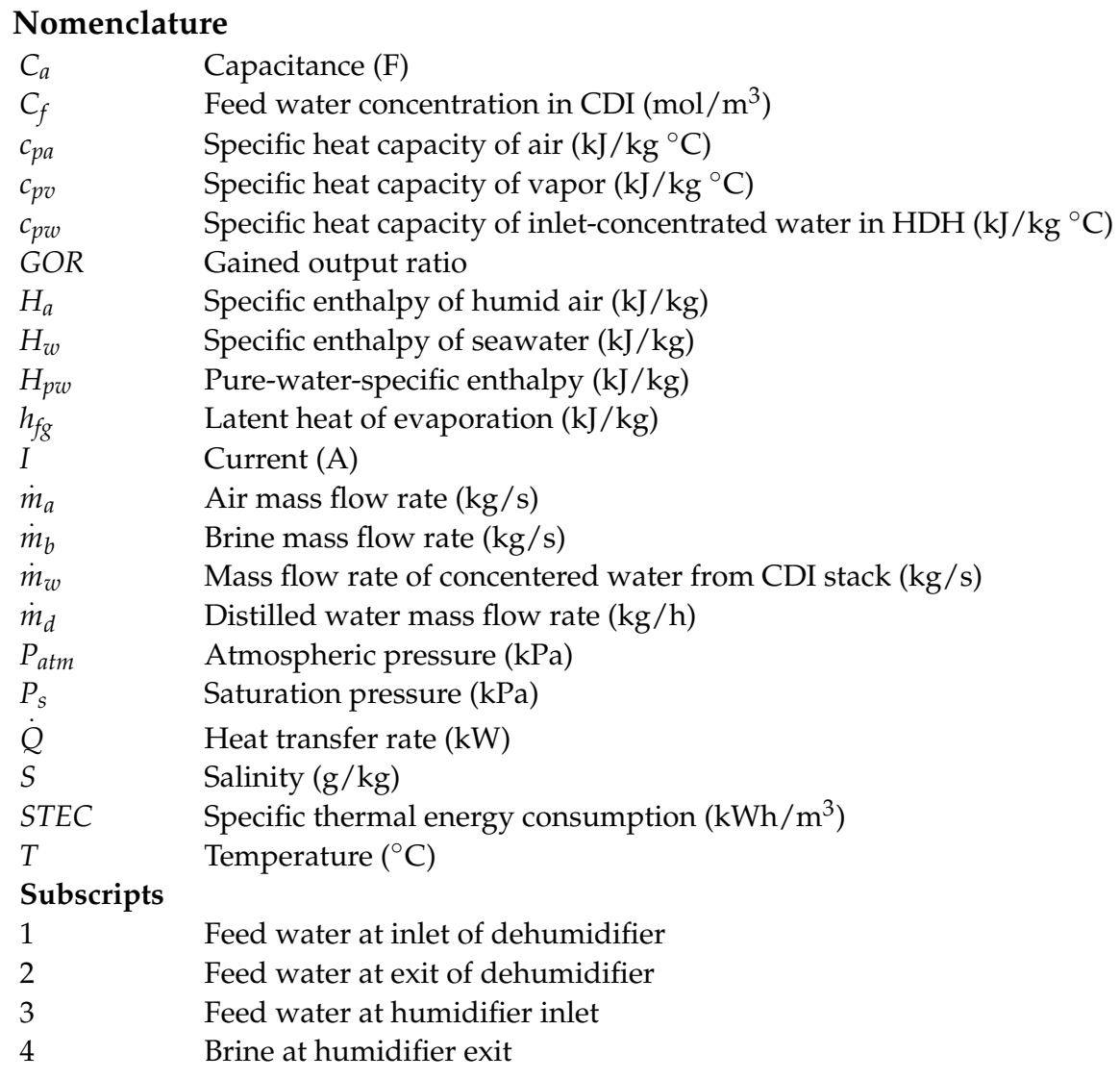




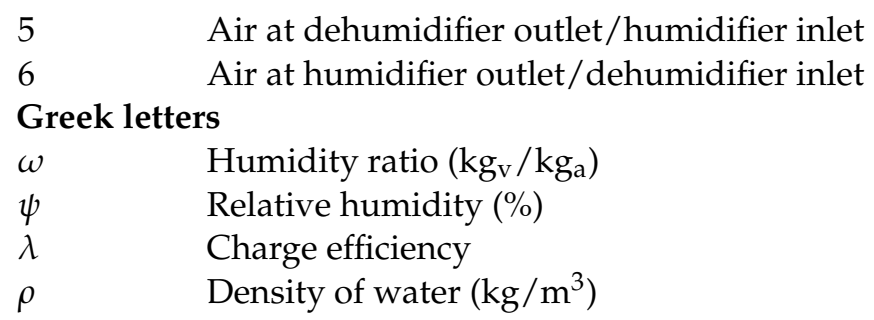

\section{References}

1. World Resources Institute. Available online: https:/ /www.wri.org/ (accessed on 20 April 2021).

2. World Health Organization (WHO). Available online: http://www.who.int/mediacentre/factsheets/fs391/en/ (accessed on 5 May 2021).

3. Aamer, A.; Ramoto, A.; Francesca, M.; Efrem, C.; Enrico, D. Membrane technology in renewable-energy-driven desalination. Renew. Sustain. Energy Rev. 2018, 81, 1-21.

4. $\quad$ Leon, A.; Sherman, M.; Randall, S.H.; Victor, V.D. Hybrid desalting systems. Desalination 1989, 76, $189-197$.

5. Muhammad, W.S.; Kyaw, T.; Young, D.K.; Kim, C.N. An experimental investigation on MEDAD hybrid desalination cycle. Appl. Energy 2015, 148, 273-281.

6. Lawal, D.U.; Jawad, S.A.; Antar, M.A. Experimental and theoretical study on a heat pump driven open-air humidification dehumidification desalination system. Energy 2020, 207, 118-252. [CrossRef]

7. Emad, A.; Jamel, O.; Abdullah, N.; Jehad, S. Enhancement of brackish water desalination using hybrid membrane distillation and reverse osmosis systems. PLoS ONE 2018, 13, 205012.

8. Jean, P.M.; Stephanie, L.; Corinne, C. Vacuum membrane distillation of seawater reverse osmosis brines. Water Res. 2010, 18, 5260-5273.

9. Lawal, D.U.; Antar, M.A. Investigation of a heat pump-driven humidification-dehumidification desalination system with energy recovery option. J. Therm. Anal. Calorim. 2021, 145, 3177-3194. [CrossRef]

10. Alessandra, C.; Enrico, D. Energetic and exergetic analysis of an integrated membrane desalination. Desalination 1999, 124, 243-249.

11. Farshad, F.; Meisam, K.; Iman, S. Experimental study of a cascade solar still coupled with a humidification-dehumidification system. Energy Convers. Manag. 2016, 115, 80-88.

12. Dahiru, U.L.; Mohamed, A.A.; Atia, E.K. Integration of a MSF Desalination System with a HDH System for Brine Recovery Sustainability 2021, 13, 3506.

13. Lawal, D.U.; Antar, M.A.; Khalifa, A.; Zubair, S.M.; Sulaiman, F.A. Experimental investigation of heat pump driven humidification dehumidification desalination system for water desalination and space conditioning. Desalination 2020, 475, 114199. [CrossRef]

14. Joel, M.M.; Ramesh, S.; Altaf, H.; Arnold, J.; Samer, A. Field evaluation of membrane distillation followed by humidification/dehumidification crystallizer for inland desalination of saline groundwater. Desalination 2016, 398, 12-21.

15. Sandeep, P.; Farid, M.; Selman, J.R.; Al-hallaj, S. Solar desalination with a humidification-dehumidification technique-A comprehensive technical review. Desalination 2004, 160, 167-186.

16. Lawal, D.U.; Qasem, N.A.A. Humidification-dehumidification desalination systems driven by thermal-based renewable and low-grade energy sources: A critical review. Renew. Sust. Energy Rev. 2020, 125, 109817. [CrossRef]

17. Jande, Y.A.C.; Asif, M.; Shim, S.M.; Kim, W.S. Energy minimization in monoethanolamine-based $\mathrm{CO}_{2}$ capture using capacitive deionization. Int. J. Energy Res. 2014, 38, 1531-1540. [CrossRef]

18. Jande, Y.A.C.; Kim, W.S. Desalination using capacitive deionization at constant current. Desalination 2013, 329, 29-34. [CrossRef]

19. Mostafa, H.S.; Mohamed, A.A.; Syed, M.Z.; Abubaker, M.E. Optimum thermal design of humidification-dehumidification desalination systems. Desalination 2014, 349, 10-21.

20. Karim, M.C.; Narayan, G.P.; Syed, M.Z.; Lienhard, J.H. Use of multiple extractions and injections to thermodynamically balance the humidification-dehumidification desalination system. Int. J. Heat Mass Transf. 2014, 68, 422-434.

21. Mostafa, H.S.; Lienhard, J.H.; Syed, M.Z. Thermophysical properties of seawater: A review of existing correlations and date. Desalin. Water Treat. 2010, 16, 354-380.

22. Hermosillo, J.J.; Bulnes, C.A.A.; Estrada, C.A. Water desalination by air humidification: Mathematical model and experimental study. Sol. Energy 2012, 86, 1070-1076. [CrossRef]

23. Sahali, M.A.; Ettouney, H.M. Humidification dehumidification desalination process: Design and performance evaluation. Chem. Eng. J. 2008, 143, 257-264. [CrossRef]

24. Hamed, M.H.; Kabeel, A.E.; Omara, Z.M.; Sharshir, S.W. Mathematical and experimental investigation of a solar humidificationdehumidification desalination unit. Desalination 2015, 358, 9-17. [CrossRef]

25. Yildirim, C.; Solmus, C. A parametric study on a humidification-dehumidification (HDH) desalination unit powered by solar air and water heaters. Energy Convers. Manag. 2014, 86, 568-575. [CrossRef]

26. Cong, S.; Cheng, J.M.; Cai, J.C.; Sun, R.S.; Dong, J.H.; Guo, F. Thermodynamic analysis and experimental study on humidificationdehumidification desalination system. J. Zhejiang Univ. (Eng. Sci.) 2019, 53, 684-691. 
27. Deghani, S.; Date, A.; Akbarzadeh, A. An experimental study of brine recirculation in humidification-dehumidification desalination of seawater. Case Stud. Therm. Eng. 2019, 14, 100463. [CrossRef]

28. Fritzmann, C.; Lowenberg, J.; Wintgens, T.; Melin, T. State-of-the-art of reverse osmosis desalination. Desalination 2007, 216, 1-76. [CrossRef]

29. Anderson, M.A.; Cudero, A.L.; Palma, J. Capacitive deionization as an electrochemical means of saving energy and delivering clean water. Comparison to present desalination practices: Will it compete? Electrochim. Acta 2010, 55, 3845-3856. [CrossRef]

30. Narayan, G.P.; Sharqawy, M.H.; Lienhard, J.H.; Zubair, S.M. Thermodynamic Analysis of humidification dehumidification desalination cycles. Desalin. Water Treat. 2010, 16, 339-353. [CrossRef]

31. Rihua, X.; Shichang, W.; Zhi, W.; Lixin, X.; Pingli, L.; Aimei, Z. Experimental Investigation of a Vertical Tubular Desalination Unit Using Humidification-Dehumidification Process. Chin. J. Chem. Eng. 2005, 13, 324-328. 